\title{
A via portuária de Salvador: mobilidade na capital baiana a partir de intervenções viárias
}

\author{
The Port Route of Salvador: mobility in the capital city \\ of the State of Bahia after road interventions
}

Aliger dos Santos Pereira Fabiano Viana Oliveira

\section{Resumo}

Este artigo analisa as contribuições do Programa de Aceleração do Crescimento (PAC) na obra rodoviária da Via Portuária (Bairro do Cabula-Salvador/ BA). Como essa obra é capaz de proporcionar maior mobilidade? Utilizou-se pesquisa exploratória e bibliográfica entre os anos de 2007 (início do PAC) a 2010 (finalização da primeira etapa do $P A C)$. Conclui-se que a obra não foi finalizada. Caso seja finalizada, proporcionará uma maior interligação entre o Porto de Salvador, a Base Naval de Aratu e o Centro Industrial de Aratu (CIA), além da região Nordeste com o Sul e Sudeste do país. Apesar de ser uma obra localizada num bairro, constitui um empreendimento que interfere nas redes de transporte intra e interurbano tanto em nível regional como nacional do país.

Palavras-chave: Programa de Aceleração do Crescimento (PAC); Via Portuária (Cabula/Salvador-BA); mobilidade.

\begin{abstract}
This paper analyzes the contributions of the Programa de Aceleração do Crescimento (PAC Growth Acceleration Program) to the construction of the Port Route (Cabula neighborhood - city of Salvador, Northeastern Brazil). How is this work able to provide greater mobility? We used exploratory and bibliographic research between 2007 (the beginning of the PAC) and 2010 (the end of the first stage of the PAC). We conclude that the work has not been completed. If completed, it will provide greater interconnection among the Port of Salvador, the Aratu Naval Base and the Aratu Industrial Center, and also between the Northeast and the South and Southeast of the country. Despite being a work located in a neighborhood, it is an enterprise that interferes in the intra and intercity transport networks both in the regional and national levels in Brazil.
\end{abstract}

Keywords: Growth Acceleration Program (PAC); Port Route (Cabula/Salvador-BA); mobility. 


\section{Introdução}

Este artigo analisa as contribuições do Programa de Aceleração do Crescimento (PAC) na área de infraestrutura rodoviária, mas especificamente a obra da Via Portuária de Salvador e sua importância para o município, o Bairro do Cabula (Salvador/Bahia) e adjacências. A partir da seguinte pergunta: será que a obra da Via Portuária de Salvador é capaz de proporcionar maior mobilidade para o Bairro do Cabula e adjacências?

0 Bairro do Cabula pertence à região administrativa, denominada XI da cidade de
Salvador. A partir da década de 1970, a localidade deixa de ser agrícola e passa a ter condomínios e residências. A Figura 1 mostra, em vermelho, sua localização, no centro da península soteropolitana, à leste da Rodovia Salvador-Feira de Santana (BR-324), chamada de Acesso Norte. É próximo de bairros como a Vila Laura, Pernambués, Saboeiro, Imbuí, São Gonçalo, Engomadeira, Mata Escura, Narandiba, Tancredo Neves e Cabula 6. 0 acesso ao bairro se dá principalmente pela Avenida Antonio Carlos Magalhães (ACM) na antiga Rótula do Abacaxi, pelo Bairro Saboeiro através da Avenida Paralela e por Narandiba pela Avenida Edgar Santos.

Figura 1 - Localização do Bairro do Cabula na cidade de Salvador e sua proximidade com a BR-324/116

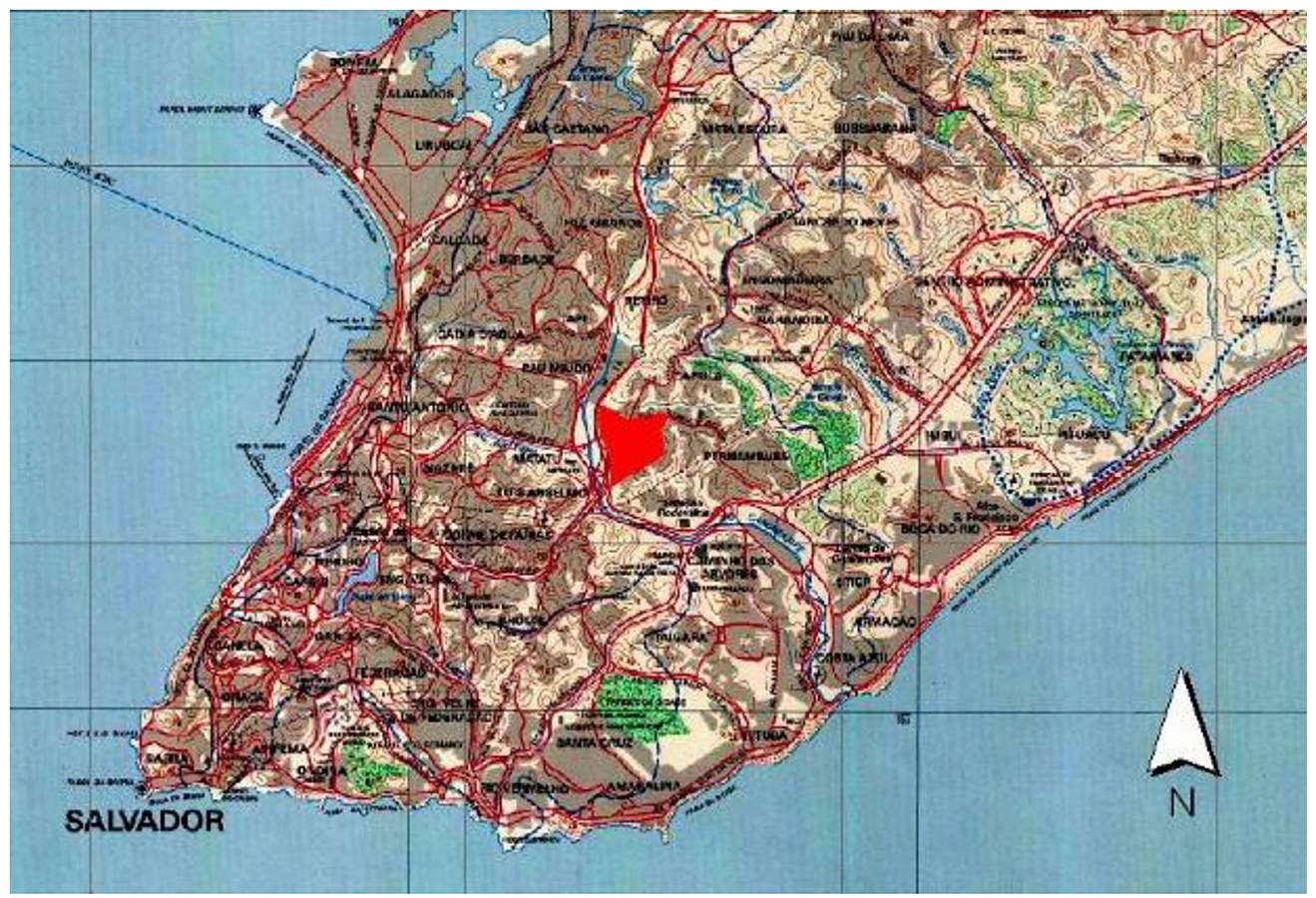

Fonte: Casa Civil (2010). 
0 objetivo deste artigo é o de identificar o que foi realizado, e as possíveis contribuições na área de mobilidade, promovidas pelo PAC, através da Via Portuária de Salvador no Bairro do Cabula e adjacências, após a finalização das obras. Para realizar a pesquisa, foi feita uma abordagem dedutiva e qualitativa através de pesquisa exploratória e bibliográfica entre os anos de 2007 até 2010.

A delimitação do estudo encontra-se entre 0 ano de 2007 a 2010, pois é o primeiro período correspondente à implantação do PAC, no Brasil e na Bahia, pelo ex-presidente Luis Inácio Lula da Silva; já 2010 corresponde à finalização da primeira etapa do PAC.

0 artigo é dividido em três partes, a primeira mostra de forma rápida o significado do PAC de infraestrutura rodoviária no Brasil, Bahia e Salvador (Banco Mundial, 1994; Benitez, 1988; Diretrizes Estratégicas da Bahia, 2010; Política Nacional de Mobilidade Urbana Sustentável, 2004; Silva,1982; Lei Federal 10.257/2001). Já a segunda parte faz um rápido histórico do Bairro do Cabula, presente no município de Salvador (Fernandes, 2004; Gottschall, 2006; Estudo de Impacto Urbano Ambiental, 2011); a terceira parte mostra os investimentos e as contribuições do PAC de infraestrutura rodoviária a partir da Via Portuária no Bairro do Cabula (Salvador/Bahia) e localidades adjacentes, bem como as possíveis contribuições dos projetos territoriais associados ao PAC caso sejam concluídos em sua integra, afinal o PAC não constitui uma política pública isolada, e sim, uma forma de interligar programas governamentais de gestão territorial em nível federal, estadual ou municipal, onde existe parceria entre os três entes governamentais.

\section{PAC e a infraestrutura da logística rodoviária na cidade de Salvador (BA)}

De acordo com o Banco Mundial (1994), a infraestrutura corresponde à parte do capital global das economias regionais e nacionais que, normalmente, não é administrada pelo mercado, e sim, politicamente. Sua importância é reforçada, pois representa um instrumento direto da política pública de ataque às disparidades regionais de desenvolvimento.

Para Benitez (1988, p. 144), a infraestrutura é a parte do capital global que combina e associa a simbologia do "capital" e do "público" para fornecer transporte, abastecimento de energia, sistema de comunicações, redes de água e esgoto, instituições de ensino, órgão de saúde, instalações de segurança, entre outros.

O PAC constitui um tipo de programa baseado no estabelecimento de parcerias público-privadas, tendo em vista que o governo, incapaz de suprir todas as necessidades de investimento em infraestrutura, repassa para o setor privado a responsabilidade do investimento de expansão e de melhoria dessa infraestrutura, segundo seus critérios de prioridade.

0 PAC é um exemplo de programa que investe em infraestrutura. Segundo o Banco Mundial (1994), quando há investimento em infraestrutura, o governo busca realizar a correção das falhas do mercado, e também estabelecer políticas para coordenar interações setoriais, com vistas a melhorar o desempenho dos serviços de infraestrutura e para promover decisões de investimentos regionais pelo capital privado. Dessa forma, espera-se que haja uma 
integração entre o capital privado e o público, em escala tanto nacional como regional.

Na sua concepção inicial, para o período de 2007 a 2010, o PAC projetou a realização de investimentos orçados em $\mathrm{R} \$ 503,9$ bilhões, sendo $R \$ 67,8$ bilhões do governo federal e $\mathrm{R} \$ 436,1$ bilhões das empresas estatais federais e do setor privado. Sem haver concretizado o que projetara (pelo menos na sua integridade), programou, em 2010, para o período de 2011 a 2014, uma "segunda" fase do PAC com previsão de investimento de $\mathrm{R} \$ 958,9$ bilhões. Após 0 ano de 2014, a estimativa é a de injetar mais $\mathrm{R} \$ 631,6$ bilhões em obras, totalizando $\mathrm{R} \$ 1,59$ trilhão, para essa segunda fase (PAC, 2010).

A Bahia foi contemplada, na primeira etapa do PAC, com recursos de $\mathrm{R} \$ 41,9$ bilhões para obras de infraestrutura, estando projetada para a segunda etapa mais $\mathrm{R} \$ 9,3$ bilhões, totalizando o valor de $\mathrm{R} \$ 51,2$ bilhões. Entre os anos 2007 até 2010, 20\% do total dos recursos do PAC de infraestrutura foram para a área logística, 47\% para a energia e 33\% para a área social (Diretrizes Estratégicas da Bahia, 2010; Casa Civil Bahia, 2010). De uma forma breve, percebe-se que os investimentos logísticos visam escoar a produção para o mercado interno e externo e expandir a infraestrutura de apoio turístico do Estado; o energético pretende garantir a segurança, a diversificação, a ampliação e a integração das fontes energéticas da Bahia e da região Nordeste; e o social urbana visa à melhoria e à ampliação das condições de vida da população da Bahia.

Os investimentos logísticos baianos estão relacionados com as rodovias, ferrovias, aeroporto e portos, em consonância com a escala nacional. Entretanto, a área de hidrovias não foi contemplada (2007-2010), pois não houve investimento do PAC-1 nessa modalidade no Estado, apesar de estar incluída no PAC-2 (após o ano de 2010). Os investimentos logísticos, segundo o Balanço de 4 anos do PAC (2007-2010), buscam ampliar a infraestrutura logística existente, com dois objetivos. 0 primeiro, o de "aumentar a competitividade regional" no que se refere ao escoamento da produção pelos portos (de Aratu e de Salvador), por algumas rodovias (BR-324, BR-101, BR-135, BR-116, BR-030) e por ferrovia (a Ferrovia de Integração Oeste-Leste), com o objetivo de integrar os modais citados, tornando-os mais dinâmicos e modernos. 0 segundo objetivo está vinculado à expansão da infraestrutura de apoio ao turismo, beneficiando o aeroporto de Salvador e algumas rodovias, as BR-324, BR-101, BR-116, BR-418 (Balanço de quatro anos..., 2010, p. 4).

0 projeto logístico do PAC baiano teve influência especialmente do Programa de Logística de Transportes do Estado da Bahia (Pelt Bahia). Esse programa buscou identificar os principais investimentos para a área de infraestrutura logística em um período entre 20 a 25 anos, de forma a promover intervenções públicas e/ou privadas, para reorganizar a cadeia logística da Bahia, com o objetivo de modificar a matriz de transporte, que em sua maioria é de caráter rodoviário, para os modais ferroviário, hidroviário e de cabotagem.

A Bahia é um dos estados pioneiros na busca de soluções para os entraves logísticos. Antes mesmo da formatação do PAC ou do Pla- no Nacional de Logística e Transportes - PNLT, ambos os programas do Governo Federal, a Bahia já demonstrava sua preocupação sobre o assunto com a formatação e divulgação do Pelt-BA (Programa Estadual 
de Logística e Transportes da Bahia), no ano de 2002. Tratava-se de um documento onde foram compilados os principais gargalos logísticos do Estado e as possíveis intervenções para a resolução de cada caso, inclusive as propostas relacionadas ao transporte. Atualmente, o PAC engloba essas ações (Carvalho, 2010). Os principais produtos do Pelt Bahia são os portfólios de investimento e o Plano Prioritário. A organização do portfólio contempla 137 projetos (2008-2020), com investimento de $\mathrm{R} \$ 7,8$ bilhões e o Plano Prioritário, mais imediatista, contemplando 71 projetos (2004-2007) com investimentos de R\$1,9 biIhões. 0 Pelt Bahia pretendia atuar em diferentes modalidades (rodovias, ferrovias, portos, hidrovias e aeroportos); além da criação de centros de distribuição de produtos no Estado. Para a questão rodoviária, existem sete grupos de intervenções. No total, serão 58 projetos, numa extensão de 5,065 km, com investimentos de $\mathrm{R} \$ 1,53$ milhões (Cerqueira, 2007, pp. 114-115).

Outro aspecto observado é que a infraestrutura logística é composta pelo eixo rodovias, ferrovias, portos, aeroportos e portos. 0 eixo rodoviário contemplou $85 \%$ dos investimentos, ou seja, $R \$ 3.413,7$ milhões, com um total de 14 obras em todo o Estado, onde a Via Portuária (Rótula do Abacaxi) constitui apenas uma das obras, com um investimento estimado inicialmente pelo governo de $\mathrm{R} \$ 43,8$ milhões, entretanto, até início de janeiro de 2012, a obra não foi totalmente finalizada e já tinha sido investido o valor de $\mathrm{R} \$ 207,7$ milhões. Então, o governo da Bahia, juntamente com os governos municipais e federais optaram pelas obras rodoviárias para promover a mobilidade dos seus cidadãos em seu território.
Atualmente, em Salvador, o trânsito e a falta de investimentos em transportes coletivos consomem entre uma e $2 \mathrm{~h}$ por deslocamento diário de $19,46 \%$ das pessoas e de 2,57\% acima de $2 \mathrm{~h}$, ficando atrás apenas de São Paulo e Rio de Janeiro (IBGE, 2010). 0 Instituto de Pesquisa Econômica Aplicada (2012) também comprova isso, quando relata que a população de Salvador tem um tempo médio de percurso casa/trabalho de 33,9 minutos diário. Caso o tempo de deslocamento dos cidadãos diminuísse, aumentaria sua qualidade de vida e melhoraria sua integração social.

A mobilidade é uma característica que deve ser associada às pessoas e aos bens, pois

[...] corresponde às diferentes respostas dadas por indivíduos e agentes econômicos às necessidades de deslocamentos, considerando as dimensões do espaço urbano e a complexidade das atividades nele desenvolvidas. (Política Nacional de Mobilidade Urbana Sustentável, 2004, p. 13)

Já a acessibilidade "é definida como o grau re- lativo de facilidade com que um ponto do espa- ço geográfico é atingido, a partir de um outro lugar" (Silva, 1982, p. 51) e a interação refere-se "[...] a todas as formas de movimento entre dois ou mais lugares".

A mobilidade urbana em Salvador e no Cabula, a partir do PAC, busca um conjunto de modos, redes e infraestruturas que garantam o deslocamento das pessoas na cidade e no referido bairro, e que seja capaz de manter fortes interações com as demais políticas urbanas. Afinal, Salvador, assim como outros centros urbanos brasileiros teve um crescimento urbano desordenado da sua cidade e de seus bairros. Além disso, a motorização crescente e o declínio dos transportes públicos estão 
comprometendo a sustentabilidade da mobilidade urbana e, por consequência, a qualidade de vida e a eficiência da economia das grandes cidades. Na ausência de políticas públicas efetivas, o desejável crescimento econômico implica em maiores níveis de congestionamento devido ao aumento da frota e da circulação de veículos. Ao mesmo tempo, a população de baixa renda está sendo privada do acesso ao transporte público, devido à baixa capacidade de pagamento e à precariedade da oferta, especialmente, para as áreas periféricas.

Salvador é uma cidade onde percebe-se grave desequilíbrio social e com parcela significativa da população sem a devida apropriação dos espaços públicos, revelados especialmente por uma dissociação entre a urbes (forma espacial e arquitetônica da cidade) e a civitas (relações humanas e políticas que nela se geram). No setor de transportes a cidade, também, enfrenta dificuldades, explicitadas, em boa parte, na gestão da mobilidade a que estão sujeitos os que aqui vivem, especialmente pela falta de instrumentos para avaliação e monitoramento desta mobilidade. (Santos, 2009, p. 16)

0 conceito de mobilidade urbana sustentável corresponde ao

[...] aspecto essencial à qualidade de vida da cidade, primeiro, por ser um fator essencial para todas as atividades humanas ; segundo, por ser um elemento determinante para o desenvolvimento econômico e para a qualidade de vida; e, terceiro, pelo seu papel decisivo na inclusão social e na equidade da apropriação da cidade e de todos os ser viços urbanos. (SeMOB, 2006)

Tal conceito é defendido pelo Estatuto da Cidade (Lei Federal 10.257/2001), pois essa lei fornece aos governos municipais mecanismos para gerenciar e combater a especulação imobiliária, o uso indevido do espaço urbano e o desrespeito aos direitos básicos do cidadão, com o objetivo de definir a função social das cidades no Brasil. Em seu artigo segundo, o Estatuto deixa claro seu caráter de inclusão urbana ao apresentar em seu primeiro parágrafo

[...] a garantia do direito a cidades sustentáveis, entendido como o direito à terra urbana, à moradia, ao saneamento ambiental, à infraestrutura urbana, ao transporte e aos serviços públicos, ao trabalho e ao lazer, para as presentes e futuras gerações,

completando no parágrafo quinto, com

[...] oferta de equipamentos urbanos e comunitários, transporte e serviços públicos adequados aos interesses e necessidades da população e às características locais. (Lei Federal 10.257/2001)

Dessa forma, o sistema de mobilidade urbana deve ser considerado como um conjunto de modos, redes e infraestruturas que garante o deslocamento das pessoas na cidade e que mantém fortes interações com as demais políticas urbanas (Bergman, 2006).

0 Estatuto da Cidade (Lei Federal 10.257/2001) define a mobilidade urbana sustentável como

[... o conjunto de políticas de transporte e circulação que visa proporcionar o acesso amplo e democrático ao espaço urbano, através da priorização dos modos não motorizados e coletivos de transporte, de forma efetiva, que não gere segregações espaciais, socialmente inclusiva e ecologicamente sustentável baseado nas pessoas e não nos veículos. (Politica Nacional de Mobilidade Urbana Sustentável, 2004, p. 13) 
Quando a mobilidade não trabalha dentro dos princípios de sustentabilidade, ela torna-se insustentável nas cidades, e favorece a segregação espacial, a deseconomia regional, o declínio da qualidade ambiental e a exclusão social, interferindo sobremaneira na qualidade de vida dos citadinos.

A Região Metropolitana de Salvador, RMS, foi instituída em 1973 pelo governo militar. A Conder foi criada para planejar e infraestruturar a região, mas falhou e perdeu o foco, sendo transformada em uma empresa para fazer obras em todo 0 Estado. A única tentativa de planejamento da RMS, o CIA, só se preocupou com a indústria, visando os incentivos da Sudene. Nenhuma atenção ao transporte, habitação, saneamento, saúde, educação, cultura e turismo. Não se pode resolver nenhum desses problemas dentro dos limites de cada município e partido, senão com políticas de estado. (Azevedo, 2009)

Percebe -se que a cidade de Salvador tem uma grande carência na sua infraestrutura de transporte urbano, que é responsável pela mobilidade, circulação e acessibilidade dos seus cidadãos. Um exemplo disso é a distribuição das linhas de ônibus da cidade, que está dividida em quatro regiões de integração, existindo maior concentração nas áreas do Subúrbio e do Miolo (68,4\%, considerando um universo de 425 linhas divulgadas no site da Transalvador). 0 restante (134 linhas) está espalhado pela Orla e Centro. Percebe-se que $67 \%$ do total das linhas (cerca de 300) registravam até 20 minutos de intervalo entre um ônibus e outro. 0 restante, 33\% (125), ficava acima dos 20 minutos. 0 tempo médio da linha foi de 2h19, considerando ida e volta, tornando o sistema de transporte da cidade ineficiente, pois os usuários do serviço encontram coletivos superlotados, percursos longos e demorados, espera excessiva nos pontos (Secretaria de Transporte e Infraestrutura, 2009).

0 PAC-2 (após o ano de 2010 ) pretende interligar os transportes fisicamente (ônibus, metrô e trem), mas também com o pagamen- to do bilhete único para quem usa os trans- portes integrados; assim o passageiro pagaria apenas uma única passagem, a segunda via- gem ou outras posteriores seriam gratuitas, desde que o passageiro se deslocasse em um período que não extrapolasse $2 \mathrm{~h}$, entre a cobrança da primeira tarifa e a integração nas outras viagens. 0 objetivo é o de melhorar não apenas os transportes, mas também a sua lotação, fazendo com que as pessoas possam realmente utilizar o transporte público e diminuam o uso do carro particular nas vias públicas. É bom ressaltar que o Cabula e a Via Portuária estão contemplados dentro desse percurso, e que, entre os anos de 1995 e 2008, ou seja, num período de 14 anos, a frota de ônibus cresceu 17,1\% , enquanto o número de passageiros transportados caiu 9,19\% e as viagens reduziram em $2,9 \%$. Tal fato fez com que, em mais de uma década, Salvador passasse a contar com mais ônibus dando menos viagens, transportando menos passageiros, o que causou elevado custo do sistema. Para se ter uma ideia, o índice de passageiros transportados por quilômetros (IPK) saiu de 2,42\%, em 1995, para 1,78\%, em 2008 (queda de 27,3\%). Como reflexo, o valor da tarifa, em 14 anos, subiu $150 \%$ e a inflação acumulada do período foi de aproximadamente 109\% (Brito, 2009). 
A razão da ineficiência do sistema de transporte rodoviário de Salvador está também relacionada com a falta de logística na distribuição das linhas, em conjunto com um trânsito cada vez mais congestionado, no qual os coletivos disputam as ruas com os mais de 600 mil automóveis (estimativa do ano de 2009). Dessa maneira, a cidade do Salvador possui um emaranhado de ruas e veículos,

[...] onde há diversas questões que interferem de modo negativo para o desenvolvimento da mobilidade urbana, abrangendo diversas áreas de conhecimento Essas questões se expressam nos congestionamentos de veículos, no alto custo das tarifas do sistema público, nos inúmeros acidentes, na segregação social, na sustentabilidade ambiental, na falta de ciclovias e pela desarticulação política administrativa de planejamento e gestão de escala metropolitana. Sendo que tal panorama possui sua raiz, devido principalmente ao tipo de modelo operacionalizado e adaptado ao longo do tempo, que prioriza a locomoção do modal motorizado individual, 0 automóvel. (Rodrigues e Campos, 2009)

\section{O Bairro do Cabula e sua relação com o município de Salvador}

Salvador é a capital da Bahia, possui a sua maior população e é a terceira cidade do Brasil, com aproximadamente 3 milhões de habitantes. Nela está o maior centro administrativo, financeiro, de comércio e de serviços do Estado, respondendo por cerca de 35,0\% da arrecadação estadual de ICMS no ano de 2009 (IBGE, 2011; SEI, 2011).
0 valor do PIB per capita do município de Salvador era de $\mathrm{R} \$ 9.239,75$ em 2007. Através da avaliação do PIB de Salvador, percebe-se que o setor agropecuário contribui com 0,1\%, a parte industrial com $14,6 \%$ e o setor de serviço com $85,3 \%$. Este último dado mostra a importância do setor terciário e do Imposto Sobre Serviços de Qualquer Natureza (ISS) para a arrecadação municipal e consequentemente para os investimentos locais em infraestrutura (como, por exemplo, o PAC). Para se ter ideia do crescimento do setor terciário em Salvador através do ISS, percebe-se que, em 2003, esse imposto correspondia a $21 \%$ da arrecadação municipal, em 2006, passou a $47,6 \%$ e, atualmente, corresponde a quase $70 \%$ da arrecadação.

A partir daí, buscou-se analisar os postos de trabalho (IBGE, 2011; SEI, 2011). Percebe-se que $19,8 \%$ da população economicamente ativa está na área de comércio, seguido pela atividade de prestação de serviços em atividades imobiliárias $(12,1 \%)$, depois os serviços domésticos $(9,6 \%)$ e, em seguida, o turismo, alojamento e alimentação com 7,4\%, a área de educação corresponde a 7,3\%, a de transporte, armazenagem e comunicação com $6,6 \%$ e a administração pública, defesa e seguridade social também com $6,6 \%$ dos ocupados. Assim, esses seis setores juntos contemplam $69,4 \%$ das vagas de trabalho do município.

Então, dado o Cadastro Central de Empresas (Cempre) do IBGE (2011), lá se consta- tou que as principais empresas que prestam serviço à cidade são distribuídas da seguinte forma: $41,5 \%$ são da área do comércio, 13,3\% das organizações que atuam em serviços administrativos e complementares e, 7,1\% prestam serviço na área de turismo, alimentação e 
alojamento. Entretanto, percebeu-se que as três citadas e mais as relacionadas com construção e atividades imobiliárias, além das atividades profissionais, científicas e técnicas, tiveram, entre 2007 e 2008, um aumento que variou entre 3 a $7 \%$ no número de empresas que foram criadas nessas quatro áreas do setor terciário.

0 aumento das empresas de construção está relacionado com as diversas construções presentes na cidade bem como com as obras do PAC.

Até a década de 1950, o Cabula era praticamente formado por fazendas produtoras de laranja. Durante o século XIX, a localidade serviu de esconderijo para escravos fugitivos que formavam o chamado Quilombo do Cabula, o que explica a origem do nome na localidade e a forte herança africana, representada pelos inúmeros terreiros de candomblé existentes na região (Fernandes, 2004).

Nesse mesmo período houve a expansão da cidade de Salvador de forma horizontal, o que propiciou a vinda de uma praga que destruiu os laranjais do Cabula, consequentemente a população da localidade promoveu uma transformação no uso do solo e na vida da localidade.

A partir da década de 1970, os órgãos públicos promoveram um processo de industrialização no sentido da região norte de Salvador, o que promoveu o crescimento do Cabula em uma área residencial e de serviço. $A$ localidade na época tinha uma população de aproximadamente 30 mil habitantes. Pode-se destacar nesse contexto a construção da nova estação rodoviária no vale do Camaragibe, a instalação do primeiro shopping center de porte (Iguatemi) nas imediações da rodoviária e a expansão imobiliária na Pituba e adjacências.
Também merece destaque a transferência de grande parte das instituições públicas do poder estadual para o Centro Administrativo da Bahia $(C A B)$, localizado em uma área do entorno de um trecho da então recém construída avenida Luiz Viana Filho (Paralela) (Gottschall et al., 2006).

Diante deste contexto, a década de 1970 foi marcada por um ritmo muito acelerado nas transformações vivenciadas pela localidade, com destaque para a implantação de grandes equipamentos públicos e/ou privados. Na área habitacional, em função da velocidade do processo de urbanização, as antigas fazendas foram sendo vendidas e divididas em lotes menores fazendo com que as antigas áreas verdes fossem substituídas por conjuntos habitacionais e também por invasões. (Estudo de Impacto Urbano Ambiental, 2011, p. 160)

A partir dos anos de 1980, o Bairro do Cabula continuou crescendo dentro dos padrões econômicos da cidade de Salvador. Para se ter ideia, o Cabula hoje possui basicamente atividades relacionadas ao setor terciário e cerca de 136 mil habitantes.

Pode-se destacar no Cabula os diversos shoppings da área (como, por exemplo, Plaza Shopping Cabula, Shopping Conexão Comercial, o Cabula Tropical Center e o Cabula Master Shopping), supermercados (por exemplo, hipermercado Wal-Mart), clínicas, restaurantes (exemplo: Paraíso Tropical, que se destaca por funcionar dentro de um sítio com uma grande horta e diversas árvores frutíferas que servem de insumos para a elaboração de pratos exóticos da culinária baiana), universidade (Uneb), escolas, serviços públicos (como, por exemplo, Posto do Serviço de Atendimento ao 
Cidadão - SAC), diversas lojas, que oferecem inúmeros produtos, e terreiros de candomblés, que servem como atividades turísticas (como por exemplo: o llê Axé Opô Afonjá, o Adê Iso, Viva Deus e o Ilê Ebi Oká). Então, a maior parte das atividades é do setor terciário. Assim, os empreendimentos desse setor estão próximos da BR-324 e da Via Portuária. Em relação à área de lazer, o Cabula possui uma

[...] completa desassistência das comunidades da vizinhança e área de influência indireta quanto a espaços públicos para o lazer - locais para o descanso e o divertimento propiciando o desenvolvimento pessoal e social. (Estudo de Impacto Urbano Ambiental, 2011, p. 205)

Entretanto, percebe-se no Bairro do Cabula um grande investimento da área imobiliária, que tem comprado as chácaras para a construção de condomínios residenciais e empresariais, como o Horto Bela Vista (em construção), próximo à Via Portuária, mostrando que a área continua se destacando por suas atividades terciárias.

\section{Os investimentos do PAC de infraestrutura rodoviária (via portuária de Salvador) no Bairro do Cabula e localidades adjacentes}

A principal obra do PAC da área de infraestrutura rodoviária presente no Cabula é a construção da BR-324/BA na Rótula do Abacaxi. É uma obra que já foi concluída a um custo de $\mathrm{R} \$ 129,5$ milhões, e está relacionada à Via Portuária de Salvador (Figura 2), que também constitui outra obra do PAC. Trata-se, portanto, da primeira via expressa da cidade de Salvador.

Nessa obra (Figura 2) foram realizadas vias elevadas sobre: a antiga Rótula do Abacaxi e a ladeira do Cabula; a linha do Metrô, a interligação do Largo Dois Leões e a Cidade Nova; 0 túnel na Ladeira da Soledade e o elevado sobre a Avenida Jequitaia e Oscar Pontes, em Águas de Meninos. Desse conjunto de obras, a interseção, localizada na Rótula do Abacaxi, constitui-se o trecho onde há um conjunto de viadutos que levará à BR-324.

A construção da BR-324/BA na Rótula do Abacaxi visou melhorar o escoamento de produtos agrícolas como soja e manufaturados. Buscou solucionar os grandes conflitos de tráfego existentes no local, com a ampliação do número de faixas da Av. Heitor Dias e da Estrada da Rainha, também pretendeu diminuir o fluxo de cargas pesadas dentro da cidade de Salvador de forma que essas cargas sigam diretamente para a zona portuária e/ou BR-324. 0 empreendimento da BR-324/BA planeja também favorecer a mobilidade dos pedestres com a construção de calçadas e ciclovias para assim proporcionar lazer à localidade e a ligação entre bairros por passarelas, potencializando a revitalização dos bairros e do comércio do entorno. Todas as obras logísticas do PAC, inclusive as rodoviárias, tiveram um estudo e o aval do Instituto Brasileiro do Meio Ambiente e dos Recursos Naturais Renováveis (Ibama).

A Figura 3 mostra que a obra geograficamente fica na parte central da cidade de Salvador, além de estar próxima à BR-324, via de ligação interestadual e regional, com sentido duplo de tráfego e três faixas de rolamento para cada lado. Futuramente ficará próximo do futuro complexo de integração de 
Figura 2 - Percurso da Via Portuária de Salvador - 2010

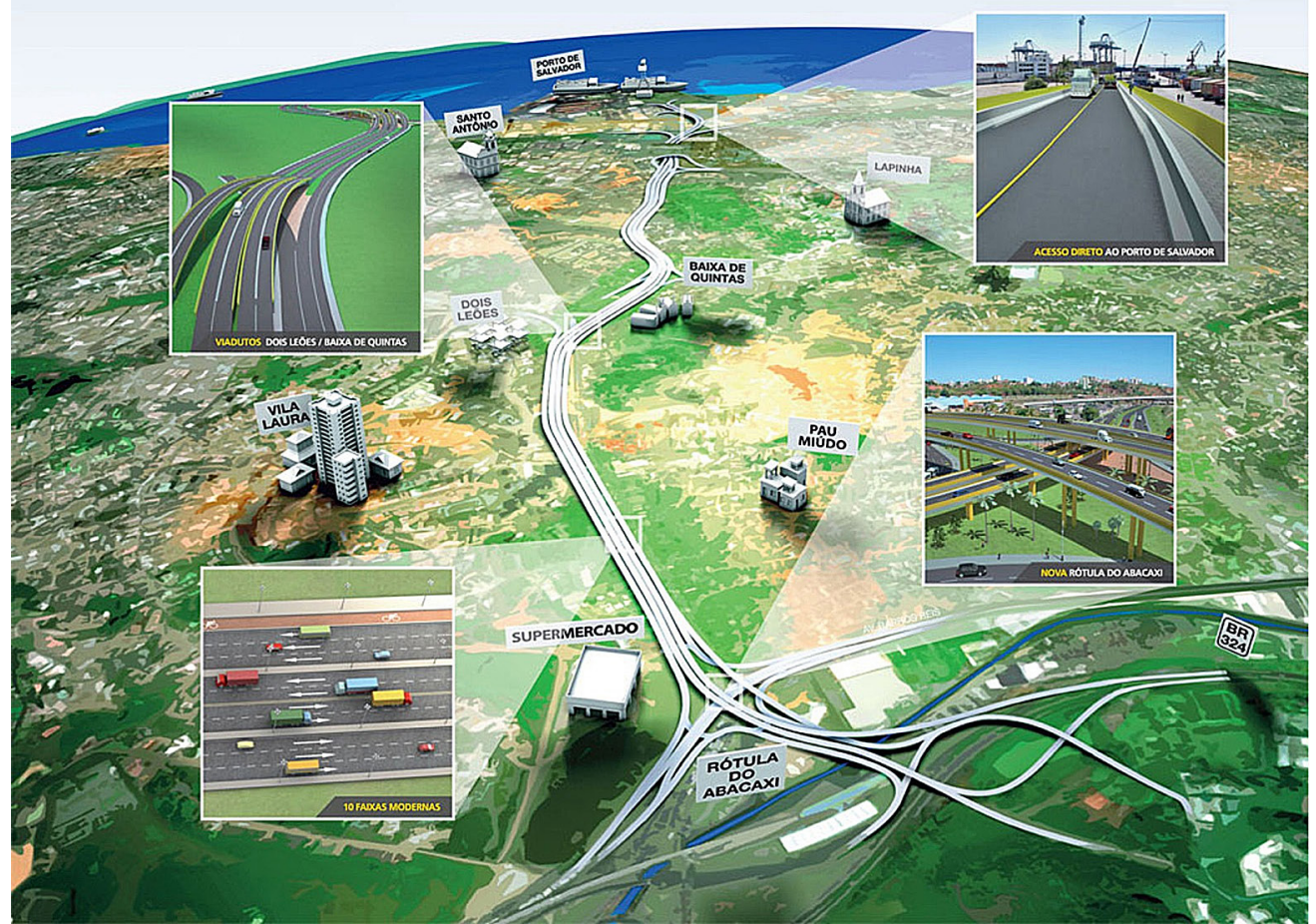

Fonte: Casa Civil Bahia (2009).

Figura 3 - Localização da Construção da BR-324/BA

na Rótula do Abacaxi - Salvador - 2010
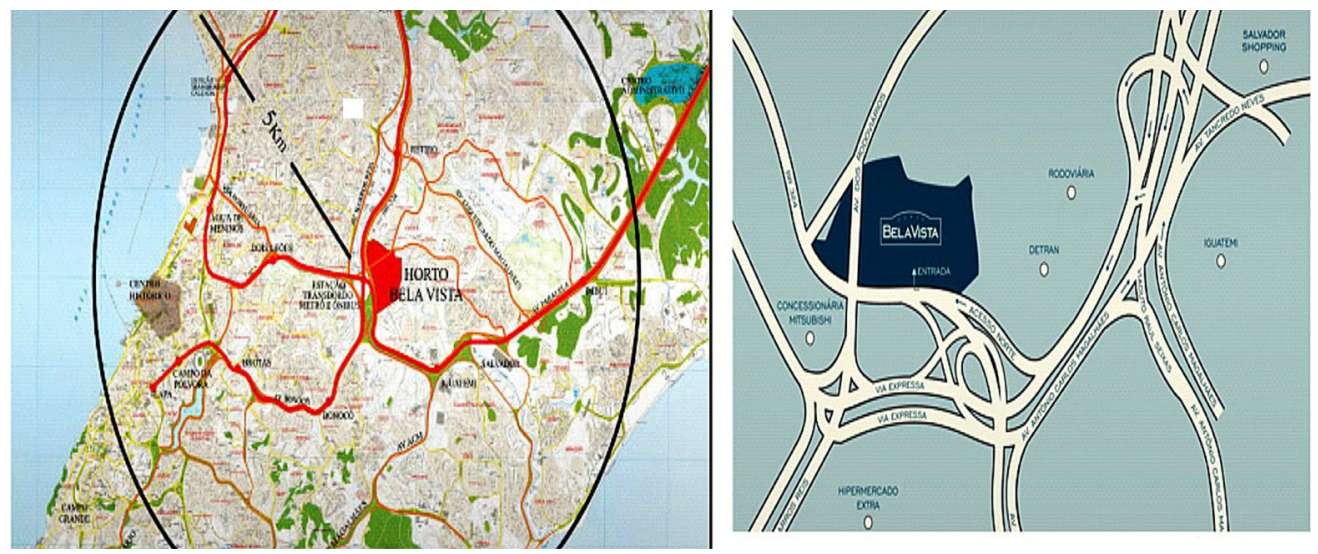

Fonte: JHSF (2010). 
transporte urbano público (metrô e ônibus), pois fica localizado nas proximidades da estação de metrô na parte denominada Acesso Norte, que integra sete estações nas regiões centro e norte da cidade, com fluxo previsto de 80.000 passageiros/dia. A obra interligará as principais avenidas da cidade (Av. Bonocô, Av. dos Rodoviários, Av. Barros Reis) de Salvador, que dão acesso a shoppings e à estação rodoviária e de transporte da cidade, de acordo com estudos (JHFS, 2010), o local tem uma população de área de influência de 2,3 milhões de habitantes, constituindo uma via coletora e também distribuidora.

A construção da Via Portuária de Salvador (BR-324/BA - Via Expressa ao Porto de Salvador), que se encontra em obras, tinha uma previsão de ter gasto, até 2010, o valor de $R \$ 43,8$ milhões, e após este ano há uma previsão de investir mais $\mathrm{R} \$ 207,7$ milhões. Entretanto, no decorrer das obras houve um replanejamento nos custos, e ela passou a ter um investimento de $R \$ 380$ milhões, sendo $\mathrm{R} \$ 340$ do PAC e R \$40 milhões do governo do Estado. Até o final de 2010, já foram gastos com a obra $\mathrm{R} \$ 274,4$ milhões, distribuídos da seguinte forma:

- R\$154 milhões para a construção dos viadutos, abertura de túneis, desapropriação de imóveis e pequenas intervenções viárias, como asfaltamento, calçamento e sinalização.

- $\mathrm{R} \$ 120,4$ milhões para o ente privado responsável pela construção. Ou seja, a construtora OAS ficou em oitavo lugar no recebimento do dinheiro total do PAC em nível nacional e auxiliou na reeleição da campanha governamental do candidato Jacques Wagner para governador da Bahia, doando 5,64\% de todo o recurso da sua campanha.
Em relação à obra do PAC da Via Portuária no final do ano de 2010, restava apenas $27,77 \%$ de investimento total da obra para ser pago, ou seja, R\$105,6 milhões. Entretanto, ainda falta:

- pagar R\$120 milhões para a OAS,

- realizar as obras de infraestrutura, urbanismo e lazer, e

- desapropriar 421 imóveis com o valor de R\$15 milhões. Sabendo-se que utilizaram $\mathrm{R} \$ 34,2$ milhões para desapropriar 350 imóveis, ou seja, cada imóvel ficou em média com $\mathrm{R} \$ 0,097$ milhões, assim, para os outros 421 imóveis, seriam necessários $\mathrm{R} \$ 40,8$ milhões, 0 que mostra a insuficiência de recursos.

Constata-se também que ainda tem R\$158 milhões para serem gastos nessa obra, e esse dinheiro é oriundo de convênio entre a Secretaria de Desenvolvimento Urbano do Estado (Sedur) com o Departamento Nacional de Trânsito (DNIT). Tal fato demonstra também a necessidade de se fazer parcerias para execução de obras grandes, mesmo que sejam órgãos governamentais.

\section{As contribuições do PAC de infraestrutura rodoviária (via portuária) no Bairro do Cabula e localidades adjacentes}

A Figura 4 mostra a importância da Via Expressa Portuária, pois auxiliará no escoamento da produção, integrando o Porto de Salvador a BR-324 e a BR-010. Percebe-se que foi uma obra iniciada durante o PAC (2007-2010) e continua em andamento, pois restam após 
0 ano de 2010,4,3Km de pista e 2,3 km de pista de rolamento. A finalização da obra com a pista de rolamento estava prevista para 30/5/2011, mas, houve um replanejamento do cronograma e a inauguração ocorreu no dia 3/11/2013.

Após a finalização das obras, a Via Expressa terá 14 viadutos, quatro passarelas, três túneis e ciclovia, visando a integração da BR-324 ao Porto de Salvador (Figuras 3 e 4), facilitando o acesso dos transportes de carga ao porto, que é um dos principais portões de escoamento da produção baiana. Entre os efeitos positivos, a obra viária irá desafogar o tráfego em áreas de grande congestionamento da cidade, a exemplo da Rótula do Abacaxi, Ladeira do Cabula, avenidas Bonocô e San Martin, Largo dos Dois Leões e Baixa de Quintas. Também haverá a criação de um novo acesso à cidade baixa da capital baiana e uma redução de 3,5 mil metros em relação ao percurso atual, que é de 7,4 mil metros.

Figura 4 - Via Expressa Portuária de Salvador - Bahia - 2009

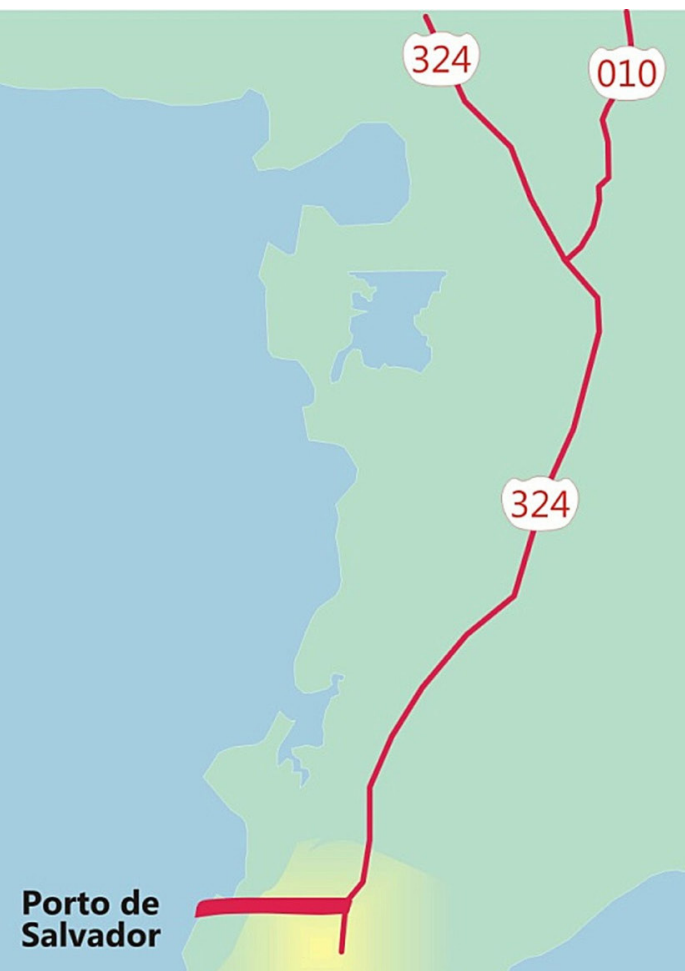

Salvador

Fonte: DNIT (2009). 
Outro aspecto dessa construção é que aproveitará a inacabada Via Portuária (Comércio) e passará pela Ladeira do Canto da Cruz, Estrada da Rainha, avenidas Glauber Rocha, Heitor Dias, chegando à antiga Rótula do Abacaxi, que fará a interligação com a BR-324. Estima-se que, quando estiver finalizada, a Via Expressa passará a receber, diariamente, 62 mil carros, sendo 3 mil de carga e 59 mil comuns, 3 milhões de contêineres, visto que hoje suporta até 250 mil contêineres.

Outro fato observado é que, em meados de 2010, houve a divulgação da obra da Ponte Salvador-Itaparica, mas essa obra não faz parte do PAC-1 e sim do PAC-2, com edital previsto para o primeiro semestre de 2011, mas, até meados de 2013, não havia recursos para a obra, apenas o planejamento. Caso essa obra seja executada, trará para a Baía de Todos os Santos o km zero da BR-242. Essa rodovia cruzará o estado da Bahia até Brasília, e terminará próxima à ponte da BR-116, sobre o Rio Paraguaçu. Assim, a obra da Ponte de Salvador-Itaparica promoveria a interligação com a Via Expressa a partir da localidade próxima ao Porto de Salvador.

Percebe-se que todas as obras do PAC rodoviário presentes neste artigo são essenciais e que já deveriam ter sido contempladas em governos passados. Já que não foram finalizadas, o sistema logístico continua ineficiente e com gargalos. Afinal, seu funcionamento apenas pode ser feito com a interligação dos vários sistemas modais.

Constata-se que a obra do PAC busca uma integração entre o transporte rodoviário, através das diversas rodovias com a parte portuária. Os principais produtos que são transportados na Via Portuária são: os móveis, os metais, os produtos químicos, os alimentos, as bebidas, as borrachas e os derivados do petróleo.

Entretanto, até o final do ano de 2010, apenas cinco viadutos foram concluídos da Via Portuária, onde um deles continua interditado. Esse viaduto tem a denominação de Viaduto 12 e liga a BR-324 à Avenida Heitor Dias, tal fato demonstra que o processo de interligação logístico se encontra ineficiente.

A Via Portuária de Salvador tem ligação direta com a BR-324. A BR-324/BA (Figuras 4 e 5) é responsável por ligar Salvador à Feira de Santana, com um fluxo médio de $18 \mathrm{mil}$ veículos por dia trafegando, onde $65 \%$ do total desses veículos são carros de passeio. Constata-se também que a BR-324/BA tem ligação com as rodovias estaduais denominadas BA-526 e BA-528, ambas com uma trajetória que chega aos terminais portuários, à Base Naval de Aratu e ao Complexo Industrial de Aratu $(\mathrm{CIA})$ - área com a presença de indústria (Figura 5).

No PAC, há também a concessão da BR116/324, tal análise é importante, pois a BR324 integra o Bairro do Cabula (Salvador), que corresponde a um dos acessos à área urbana da cidade de Salvador, assim a concessão visa integrar os municípios de: Amélia Rodrigues, Candeias, Conceição do Jacuípe, Feira de Santana, Salvador, Santo Amaro, São Sebastião do Passé e Simões Filho, melhorando a mobilidade entre eles. A Rodovia BR-116 possui cinco pedágios, localizados nos municípios de: Santo Estevão - BR-242, Milagres - Brejões, Jequié Manuel Vitorino, Poções - Planalto, Veredinha - Cândido Sales. Já a Rodovia BR-324 possui dois pedágios situados em: Simões Filho acesso a Candeias e Jacuípe (BA-515) - Amélia Rodrigues. 
Figura 5 - Ligação da BR 324/BA com rodovias estaduais e os terminais portuários

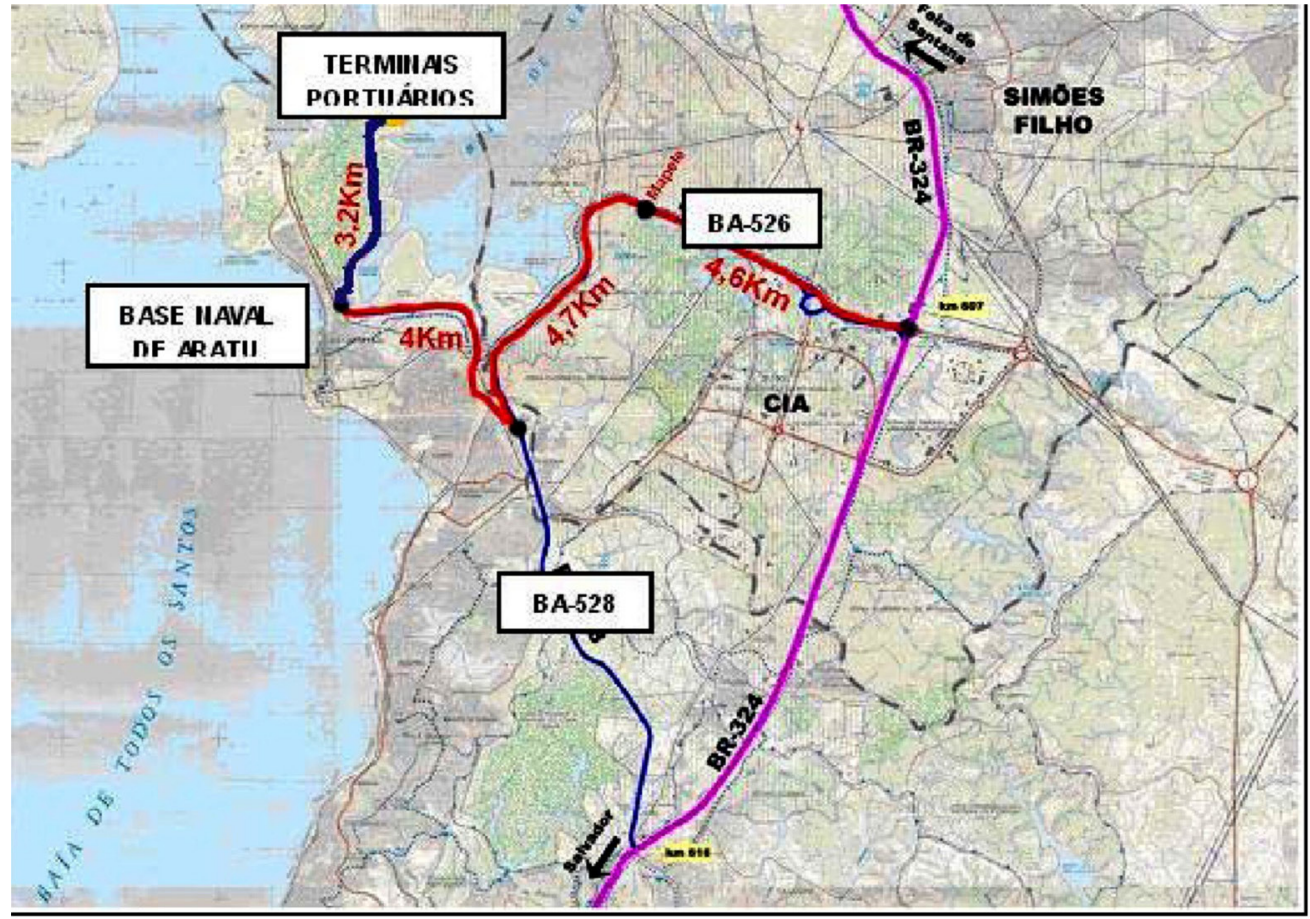

Fonte: ANTT (2008).

Os pedágios também serão distintos.Quem quiser viajar de Salvador para Feira de Santana, terá que arcar com $\mathrm{R} \$ 3,40$, sendo $\mathrm{R} \$ 1,70$ em cada trecho médio de $60 \mathrm{~km}$. Para percorrer entre Feira e a fronteira com Minas, serão mais $\mathrm{R} \$ 11-\mathrm{R} \$ 2,20$ em cada trecho, nas praças de Santo Estevão, Milagres, Manoel Vitorino, Poções e Veredinha. Para veículos como ônibus, caminhões e carretas, o valor ainda não está definido. (Pitombo, 2009)

A concessão da BR-116-324 busca também o desenvolvimento econômico nos estados da Bahia e Espírito Santo, bem como das indústrias locais e dos produtores agrícolas e de celulose. Facilitará ainda a integração regional, dada a importância da BR-116 para a ligação do transporte rodoviário entre o Nordeste e as regiões Sudeste e Sul do país, pois trata-se de uma via de passagem. Além disso, a obra alavancará o desenvolvimento da área de influência da Região Metropolitana de Salvador, que detém 70\% do PIB do Estado.

A concessão busca um modelo de gestão da rodovia através de parcerias federal, estadual e privado, onde o ente privado ficaria com os riscos de gestão, e o governo apenas com a fiscalização e o controle da rodovia de forma a: melhorar os custos de manutenção e 
logístico da rodovia para tornar os produtos regionais mais competitivos, promover a redução dos acidentes, através da melhoria das rodovias, devido à implantação de dispositivos de segurança.

A Rodobahia, empresa que ganhou a concessão da BR-116/324, deve duplicar a BR116 e a BR-324 de forma a propiciar segurança aos cidadãos. De acordo com o Edital da Agência Nacional de Transportes Terrestres (2008), a BR-116 deve ter a capacidade mínima de 28.000 veículos/dia e a BR-324 a capacidade de 70.000 veículos por dia.

0 atraso da Via Portuária se deu por causa de três motivos principais: a greve dos funcionários da construção civil por melhores condições de trabalho e melhores salários, ocorrida entre março e maio de 2010; a desapropriação dos imóveis localizados na Avenida Heitor Dias, relacionados com os bairros da Sete Portas, o Largo Dois Leões, a Baixa de Quintas e também na Estrada da Rainha; e as chuvas que ocorreram em Salvador no mesmo período da greve da construção civil. Em relação à desapropriação, constatou-se que

Do total de 771 imóveis a serem derrubados, 350 já foram desapropriados, representando um gasto com indenizações de $R \$ 34,2$ milhões, dos $R$ \$49,5 milhões previstos. A expectativa é que as próximas indenizações comecem a par tir de fevereiro deste ano. Um dos principais impasses é o fato de a maioria dos proprietários residentes não ter documentação de posse regularizada, e comerciantes apresentarem resistência em aceitar a indenização do Estado (Conder), sob a alegação de que os valores oferecidos estão abaixo do estipulado pelo mercado. (Jornal A Tarde, 2010)
Apesar de as pessoas alegarem que as indenizações possuem valor abaixo do mercado, ${ }^{1}$ em conversa informal com os negociantes da região, percebe-se que muitas casas estão para desabar, ou não tem a documentação de posse, ou seus proprietários estão resistindo para receber o pagamento das indenizações. Caso o cidadão desapropiado entre na justiça, os processos são favoráveis ao governo, em nome do res public.

No caso dos proprietários de imóveis, que apresentam risco iminente de desabamento, eles mostram-se ansiosos para receber o mais rápido possível a indenização da Companhia de Desenvolvimento Urbano do Estado da Bahia (Conder). Com relação aos imóveis sem documentação, percebe-se que as pessoas já os habitam em períodos cuja média é de aproximadamente 35 anos, e nunca se preocuparam em regularizá-los. Então, torna-se necessária a regularização desses em cartório, caso contrário serão desapropriadas por ordem de um mandato judicial. Aquelas que tiverem o documento regularizado, a Conder depositará o dinheiro no Banco do Brasil referente ao valor do respectivo imóvel. Afinal, na gestão territorial, os interesses individuais não podem sobrepor as necessidades coletivas.

Outro fato constatado é que a Conder já realizou diversas visitas aos imóveis dessa região, mas ainda não definiu como será a desapropriação, se de forma total ou parcial. Consequentemente, a Conder também não estipulou quando será realizada a indenização e qual o valor a ser pago por esses imóveis. Mas a população deve sair dos imóveis em nome do bem coletivo.

A obra da Via Portuária, também estará integrada com as questões de mobilidade 
intraurbana. As ações serão consolidadas em dois grandes planos: Rede Integrada de Transporte (RIT), Sistema BRT (Bus Rapid Transit) e Programa de Obras Viárias (Provia).

A RIT prevê a implantação de um Sistema Multimodal de Transporte de Passageiros. As principais ações compreendem a modernização dos trens do Subúrbio Ferroviário; a complementação da linha 1 do Metrô (Lapa/Acesso Norte), atingindo o percurso de $12 \mathrm{~km}$ entre Lapa e Pirajá; e a revitalização do Plano Inclinado (Liberdade/Calçada), que constitui um meio de transporte similar ao bonde, mas com duas cabines para transportar passageiros.

0 sistema BRT estava planejado para um total de $135 \mathrm{~km}$ de corredores de ônibus. $\mathrm{Na}$ primeira fase, serão $36 \mathrm{~km}$ de vias segregadas para ônibus, que contemplarão as avenidas Paralela, ACM, Juracy Magalhães, Barros Reis e Vasco da Gama. Já na segunda etapa, 44 km de vias percorrerão as avenidas Jorge Amado/ Edgar Santos, Pinto de Aguiar/São Rafael, Gal Costa, Dorival Caymmi/São Cristóvão e Barroquinha/Sete Portas/Heitor Dias (próximo ao Cabula e a Via Portuária). Mas devido aos interesses internacionais das empresas relacio- nadas à Federação Internacional da Copa do Mundo (Fifa), esse será substituído por metrô de superfície, para contemplar a copa de 2014. É bom esclarecer que tal decisão foi tomada após audiência pública, levando-se em consideração as questões orçamentárias do Estado.

Posteriormente, mais $55 \mathrm{~km}$ de vias (denominado Rota Fluida) serão implantados com propostas de adequação viária para dar maior fluidez à circulação dos ônibus e ao tráfego de veículos em geral, abrangendo as avenidas Silveira Martins, Afrânio Peixoto (Suburbana),
Orla Marítima, Aliomar Baleeiro (E.V.A.) e São Caetano, dentre outras avenidas. Está prevista também a extensão ao município de Lauro de Freitas, apoiada nos $9 \mathrm{~km}$ iniciais da Estrada do Coco (BA-099), e ao Aeroporto Internacional.

Já o programa Provia também estará ligado com a Via Portuária, ele será voltado para tentar solucionar os maiores engarrafamentos da cidade na região do Iguatemi, Bonocô e Paralela e ainda incrementar as soluções de trânsito rápido com cerca de 59 quilômetros de cinco novas vias para o trânsito rápido, sendo as principais: a Linha Viva e a Avenida Atlântica. Para isso, serão duplicados $33 \mathrm{~km}$ de avenidas existentes, preparadas para receber o Sistema BRT; execução de novas conexões viárias em desnível nos pontos críticos do Iguatemi, Bonocô, Lucaia, Parque da Cidade, Jardim dos Namorados, Jardim de Alah e Paralela.

Está prevista também a construção de uma nova via expressa, chamada de Linha Viva (metrô de superfície) e estará associada à Pro- via), que será mais uma alternativa à Avenida Paralela, com 20 quilômetros de pista dupla, com três faixas de tráfego por sentido, ligando Bonocô e Rótula do Abacaxi ao Aeroporto. Construída sob o regime de PPP, terá cobrança de pedágio. 0 tempo total estimado de des- locamento não ultrapassará os 15 minutos, beneficiando uma população de 780 mil mo- radores, residentes na sua área de influência direta. Será implantada na faixa de domínio das linhas de transmissão da CHESF, com nove conexões com o sistema viário existente: viadutos, alças e rampas; vinte ligações viárias simples, por viaduto. Também funcionará como opção de apoio à Avenida Paralela (liga a cidade de Salvador ao Aeroporto Luis Eduardo 
Magalhães), estabelecendo uma ligação direta do Centro Tradicional e Histórico de Salvador ao CIA-Aeroporto (BA-526) e ao novo trecho da Estrada do Côco (BA-099), através de sua conexão com a Avenida Mário Leal Ferreira (Vale do Bonocô), permitindo uma alternativa de trânsito sem necessidade de utilizar a região do Iguatemi. Atende, também, aos bairros de Pernambués, Cabula, Retiro, Saboeiro, Narandiba, Imbuí, CAB, Sussuarana, S. Rafael/S. Marcos, Parque de Pituaçu, "Miolo" de Salvador, Centro Tecnológico da Bahia, Alphaville II, Bairro da Paz, Mussurunga e São Cristóvão. Por ser um sistema de metrô, danifica menos o meio ambiente do que o transporte motorizado e é mais rápido no seu trajeto.

Com base no apresentado, percebe-se que o PAC visa melhorar a política de mobilida- de urbana de forma a reordenar o uso do solo para reduzir viagens motorizadas, o incremento do uso do transporte público coletivo e o es- tímulo aos modos não motorizados. Uma das consequências importantes da adoção dessa política seria um menor número de ônibus e carros circulando na cidade, sendo substituído pelo metrô, BRT e Provia, o que resultaria com certeza, em uma melhoria da qualidade ambiental, já que utilizaria o metrô e menos veículos motorizados. Complementarmente, essa política de descentralização deverá promover a redução de percursos, estimulando dessa maneira o uso dos modos não motorizados, não só para o lazer, mas para o trabalho, pelas facilidades criadas para os deslocamentos de ciclistas e pedestres. Para isso, seria necessário um tratamento responsável para os deslocamentos a pé e de bicicleta, como modos de transporte, com vias exclusivas, iluminadas e sinalizadas e com planejamento específico para o pedestre e para as bicicletas, reduzindo-se gastos com combustível e, consequentemente, a poluição atmosférica, recriando-se uma nova qualidade de vida. Pois até o momento as políticas beneficiaram os veículos motorizados.

\section{Conclusão}

A Via Portuária de Salvador é uma obra que promove a mobilidade tanto intra como interurbana. A obra não foi concluída até o final de 2010, pois apenas 5 viadutos foram inaugurados de um total de 14. De acordo com o planejamento governamental, até o final de 2011, a Via Portuária teria todos os seus viadutos funcionando. Mesmo não estando concluída, ela viabilizará o trânsito na localidade. Entretanto, os efeitos da sua integral mobilidade somente ocorrerão a partir do momento em que sejam concretizados os projetos rodoviários e portuários integrados a ela.

Como os projetos rodoviários interurbanos, relacionados à Via Portuária, têm relação direta com a BR-324, a concessão da BR-324/116, por exemplo, promoverá a interligação dos municípios Salvador e Feira de Santana de forma mais ágil, além dos municípios adjacentes à BR-324/116. A BR-324 também promoverá a proximidade com os portos de Salvador, a Base Naval de Aratu e o CIA; além de interligar de forma mais eficiente a região Nordeste com o Sul e o Sudeste do país.

Em nível intraurbano, percebe -se que já há a diminuição do tráfego na região, e se os projetos do RIT, Provia e Linha Verde forem concretizados, haverá uma maior descentralização das rotas de transporte presentes em Salvador, propiciando um transporte de maior 
mobilidade e acessibilidade, pois integrará o miolo da cidade com a área central; a faixa da Orla Atlântica; a parte antiga da cidade, o Subúrbio Ferroviário e o Aeroporto Luis Eduardo Magalhães. Os projetos da RIT, Provia e Linha Verde, embora promovam menos mobilidade, contaminam mais o meio ambiente, quando comparados ao metrô, eles são financiados através do PAC-2 e estão interligados com a Via Portuária.

Caso a Ponte que liga Salvador-Itaparica fique pronta, a Via expressa será importante, pois ligará Salvador a Brasília através da BR342, uma vez que, apesar de a obra fazer parte do planejamento do PAC-2, o governo ainda não tem recursos para a ela. Se for executada, trará para a Baía de Todos os Santos o km zero da BR-242. Essa rodovia cruzará o estado da Bahia até Brasília, e terminará próxima à ponte da BR-116, sobre o Rio Paraguaçu. Assim, a obra da Ponte de Salvador-Itaparica promoveria a interligação com a Via Expressa a partir da localidade próxima ao Porto de Salvador.
Outro aspecto a ser considerado é que as cargas portuárias não entrarão mais na zona intraurbana da cidade de Salvador, pois a Via Portuária direciona a carga diretamente para o Porto, havendo maior segurança para os cidadãos, já que muitas cargas possuem produtos químicos e derivados de petróleo e elas não transitarão na cidade.

Caso todos os projetos associados à Via Portuária forem concretizados, diminuirão as distâncias e o tempo de deslocamento dos cidadãos/usuários e dos produtos transportados tanto em nível intra como interurbano, consequentemente os custos de deslocamento serão diminuídos e o preço do produto final também, assim os cidadão terão mais tempo para atividades de lazer pessoal, além de utilizar transportes coletivos de maior qualidade e acessibilidade para todos. A Via Portuária, apesar de ser uma obra local, situada no Bairro do Cabula (Salvador), constitui um empreendimento que interfere nas redes de transporte logístico tanto em nível regional como nacional.

\footnotetext{
Aliger dos Santos Pereira

Universidade do Estado da Bahia, Instituto Baiano de Ensino Superior e Universidade Salvador. Salvador/BA, Brasil.

p.gaba@uol.com.br
}

\section{Fabiano Viana Oliveira}

Centro Universitário Jorge Amado e Instituto Baiano de Ensino Superior. Salvador/BA, Brasil. fvianaoliveira@uol.com.br 


\section{Nota}

(1) A Companhia de Desenvolvimento Urbano do Estado da Bahia (Conder) fez uma pesquisa de mercado e identificou e registrou $95 \%$ dos imóveis dessa região, descrevendo suas características e estabelecendo o quanto valem a partir de uma comissão julgadora, cujo responsável pela avaliação, Nei Cardim, é também membro do Conselho Federal de Economia.

\section{Referências}

AZEVEDO, P. O. de (2009). A Grande e a pequena Salvador. Disponivel em:< http://terramagazine. terra.com.br/interna/0,,Ol4076265-El6578,00-A+Grande+e+a+Pequena+Salvador.html>. Acesso em: 22 out 2010.

BALANÇO de 4 anos do PAC (2007-2010). 68 slides. Disponível em: <http://docs.google.com/viewer?a $=\mathrm{v} \& \mathrm{q}=$ cache:4YS8YR9Eotg $:$ www.brasil.gov.br/pac/relatorios/estaduais/bahia-1/bahia-balancode-4-anos+BALAN\%C3\%87O+DE+4+ANOS +DO+PAC+Bahia\&hl=pt-BR\&gl=br\&pid=bl\&srcid=ADG EESgCOVZjyaZFSdAdL--KXULddFqxsA8aCvNLfwSaFQycBda2FnY_o9qNOmCAJWKV-IkB_GxQk4k4x-uLF1oYWLZIXquiSH8iqejcb8LK1yAPLdsAQR7WLjOONvWX7ve7X7MZASv\&sig=AHIEtbSOo6til UbforySTGyDFZW_JzfPuQ>. Acesso em: 15 jul 2012.

BANCO MUNDIAL (1994). World Development Report 1994: Infrastructure for development. Washington.

BENITEZ, R. M. (1998). O capital social fixo como insumo do desenvolvimento regional. Revista Econômica do Nordeste. Fortaleza, v. 29, n. 2, pp. 143-157.

BERGMAN, L. e RABI, N. I. A. de (2006). Mobilidade e política urbana: subsídios para uma gestão integrada. Rio de Janeiro, IBAM/Ministério das Cidades.

BRASIL (2001). Lei Federal no 10.257, 10 de jul 2001. Regulamenta os arts. 182 e 183 da Constituição Federal, estabelece diretrizes gerais da política urbana e dá outras providências. Brasília, Presidência da República. Disponível em: <http://www2.senado.gov.br/sf/legislacao/legisla/.>. Acesso em: 5 jul 2010.

(2005). Estatuto da Cidade: guia para implementação pelos municípios e cidadãos: Lei n. 10.257, de 10 de julho de 2001 que estabelece diretrizes gerais da política urbana. Brasília, Câmara dos Deputados.

BRITO, A. (2009). (org.). O poder da cidade: limites da governança urbana. Salvador, EDUFBA.

CARVAlHO, L. S. de (2010). Panorama Logístico do Estado da Bahia. Disponivel em: http://www. sitedalogistica.com.br/news/panorama-logistico-do-estado-da-bahia-/. Acesso em: 10 dez 2010.

CASA CIVIL BAHIA (2000). Informações e Relatórios sobre o PAC da Bahia de infraestrutura (20072010). Disponível em: http://www.casacivil.ba.gov.br/. Acesso em: 15 jul 2010. 
CERQUEIRA, A. dos S. (2007). Fatores determinantes do transporte rodoviário intermunicipal de passageiros na Bahia: ameaças para a sustentabilidade e qualidade na prestação do serviço. Dissertação de mestrado. Salvador, Universidade Federal da Bahia.

CHURCH, J. M. e WARE, R. (2000). Industrial organization: a strategic Aprroach. Irwin McGraw Hill, Homewood, IL.

DEPARTAMENTO NACIONAL DE INFRAESTRUTURA DE TRANSPORTE (DNIT). Disponível em:< http:// www1.dnit.gov.br/>. Acesso em: 5 dez 2010.

DIRETRIZES ESTRATÉGICAS DA BAHIA (2010). Recuperar e ampliar a infraestrutura econômica e a logística: plano plurianual de 2008-2011 da Bahia. Seplan.

EDITAL DA AGÊNCIA NACIONAL DE TRANSPORTES TERRESTRES (ANTT) (2008). Governo Federal.

ESTUDO DE IMPACTO URBANO AMBIENTAL(EIUA): para o empreendimento do Horto Bela Vista (2011). Salvador.

FERNANDES, R. B. (2004). O crescimento urbano em salvador e os impactos ambientais na formação do Cabula - bairro popular estratégico da cidade. Disponível em: <http://www.ub.es/geocrit/ b3w-521.htm>. Acesso em: jan 2009.

GOTTSCHALL, C. S. et al. (2006). Centro da Cultura de Salvador. Salvador, EDUFBA/SEI.

INSTITUTO BRASILEIRO DE GEOGRAFIA E ESTATISTICA (IBGE) (2010). Disponível em :< www.ibge.gov. $\mathrm{br} />$. Acesso em: 15 jan 2010.

(2011). Indicadores de Desenvolvimento dos municípios brasileiros. Disponível em: http:// www.ibge.gov.br/home/. Acesso: 15 jan 2011

(2012). Indicadores de Desenvolvimento Sustentável. Rio de Janeiro.

INSTITUTO DE PESQUISA ECONÔMICA APLICADA-IPEA (2012). Transporte Urbano e Inclusão Social: elementos para políticas públicas. Rio de Janeiro.

JHSF (2010). Disponível em: <http://www.belavistashopping.com.br/localizacao.asp>. Acesso em: 14 mar 2011.

JORNAL A TARDE (2010). Desapropiação das obras da Via Portuaria. Cidades, 23 jan.

PITOMBO, J. P. (2009). Desafios e percalços das BRs 324 e 116. A Tarde. Economia, 25 jul.

PLANO DIRETOR DE DESENVOLVIMENTO URBANO (PDDU). Disponível em:<<http://www.sedham. salvador.ba.gov.br/lei7400_pddu/>. Acesso em: 12 out 2009.

POLITICA NACIONAL DE DESENVOLVIMENTO URBANO (PNDU) (2004). Ministério das Cidades, v. 1.

PROGRAMA DE ACELERAÇÃO DO CRESCIMENTO (PAC). Disponível em: <http://www.brasil.gov.br/ac/ conheca/>. Acesso em: 10 jan 2009.

RODRIGUES, L. e CAMPOS, M. (2009). Fluxos urbanos: arte e arquitetura em locais de movimento (Região Leste de Vitoria). Disponível em:< http://revistamdc.files.wordpress.com/2009/07/ larissa-rodrigues_cicau.pdf>. Acesso em: 12 out 2009.

SANTOS, O. B. (2009). Indicadores de mobilidade urbana: uma avaliação da sustentabilidade em áreas de Salvador. Dissertação de mestrado. Salvador, Universidade Federal da Bahia. 
SECRETARIA DE INFRAESTRUTURA DO ESTADO DA BAHIA (SEINFRA) (2009). Disponível em: http:// www.seinfra.ba.gov.br/. Acesso em: $10 \mathrm{dez} 2009$.

SECRETARIA DE TRANSPORTE E INFRAESTRUTURA (SETIN). Seminário de Planejamento da infraestrutura da cidade de Salvador. Disponível em: http://www.urbanizacao.salvador.ba.gov.br/index. php?option=com_content\&task=view\&id=37\&/temid=127. Acesso em: 15 out 2009.

SECRETARIA NACIONAL DE TRANSPORTE E MOBILIDADE URBANA - SeMOB (2006). Gestão integrada da mobilidade urbana. Brasília, Ministério das Cidades.

SISTEMA INTEGRADO DE ADMINISTRAÇÃO FINANCEIRA DO GOVERNO FEDERAL (SIAFI). Disponível em:http://www.tesouro.fazenda.gov.br/siafi/index.asp. Acesso em: 20 jun 2009

SILVA, S. C. B. de M. (1982). Cartografia da Acessibilidade e da interação no Estado da Bahia. Geografia, v. 7, número $13 / 14$, pp. 51-74.

SUPERINTENDÊNCIA DE ESTUDOS ECONÔMICOS E SOCIAIS DA BAHIA (SEI). Disponivel em: http:// www.sei.ba.gov.br/. Acesso em: 15 jan 2010

SUPERINTENDÊNCIA DE ESTUDOS ECONÔMICOS E SOCIAIS DA BAHIA (SEI) (2011). Primeiros resultados do Censo de 2010. 23 slides. Atualizado em 4 maio 2011. Disponível em: http://www.sei.ba.gov. br/index.php?option=com_content\&view=article\&id=850\&Itemid=329. Acesso em: 30 jun 2011

TRIBUNAL SUPERIOR ELEITORAL (TSE). Disponível em: < www.tse.gov.br/>. Acesso em: 14 fev 2011.

Texto recebido em 5/ago/2013

Texto aprovado em 9/set/2013 